\title{
Effects of papaverine on the retinal microcirculation
}

\author{
T. J. FFYTCHE, G. J. BULPITT, D. ARCHER, E. M. KOHNER, AND \\ G. T. DOLLERY \\ M.R.C. Clinical Pharmacology Research Group, Royal Postgraduate Medical School, London
}

Many pathological changes in the retina which give rise to visual deterioration are caused by circulatory disturbances. A number of vaso-active substances have been suggested for the treatment of these disorders in an attempt to increase the flow of blood through the eye. One such substance is papaverine which has been used in the management of acute occlusions of the central retinal artery (Varley, Holt-Wilson, and Watson, I968, Gombos, 1970) and in chronic ischaemic conditions of the choroid and retina, when it has been given by arterial, venous, oral, and retrobulbar routes. Little effort, however, has been made to investigate the action of papaverine on the retinal blood vessels, and, aparc from observations by several authors on its dilating effects (Frayser and Hichkam, I965 de Rivas Cherif, I967; Zahn, I966), no quantitative assessment or analysis of the responso of the retinal circulation to papaverine infusions has yet been reported.

The present experiments were designed to measure the effect of both local and systemic administration of papaverine on the retinal blood flow, so that an appraisal of its possible value in the management of retinal vascular disease can be made.

\section{Method}

Studies were carried out on seventeen young pigs aged between 6 and 12 weeks with weights varying from $\mathrm{I} 2$ to $30 \mathrm{~kg}$. and on three mature rhesus monkeys. The pig was chosen as the main experimental animal for several reasons. The eye is similar in size and form to that of man; the fundus lacks a tapetum and is moderately pigmented and this allows photographs of good contrast to be taken of the retina, and considerable experience has been gained in using this animal for experimental work on the retina (Ashton, Dollery, Henkind, Hill, Paterson, Ramalho, and Shakib, r966). The animals are easy to obtain and their management is not difficult. There is, however, no central retinal artery, the retinal vessels arising from the main ciliary arteries which pierce the sclera around the optic disc. Small amounts of smooth muscle are present in the walls of the larger arteries and there is a trilaminar capillary network together with a well-marked radial peripapillary plexus arising from the intraretinal arterioles (Henkind, 1967; Rootman, 1971).

Anaesthesia was induced in both types of animal by intravenous 5 per cent. sodium thiopentone and continued after tracheal intubation by further thiopentone injections through a leg vein catheter. Ventilation was maintained using a Palmer pump adjusted to keep the blood gases at normal levels and, to control this, serial measurements of the blood $\mathrm{pO}_{2}, \mathrm{pCO}_{2}$, and $\mathrm{pH}$ were made with a Radiometer BMS 3 analyser.

The systemic blood pressure and pulse rate were recorded by means of a strain-gauge transduce and Devices $\mathrm{M}_{4}$ recorder connected to a $\mathrm{P} 60$ catheter inserted into the aorta via the femoral artery. 


\section{Eye preparation}

The eye was prepared for photography by dilating the pupil with Mydrilate (Cyclopentolate I per cent.) eye drops. The position of the eye was controlled by using a modified Flieringa ring sutured to the sclera at the limbus (Fig. I). Four stay sutures were attached to the projecting parts of the ring and these served to anchor the eye to a ring of four micromanipulators. By this method it was possible to adjust the position of the eye to allow different areas to be studied without causing distortion of the globe or elevations of intraocular pressure. Clarity of the cornea was maintained by continuous saline drip.

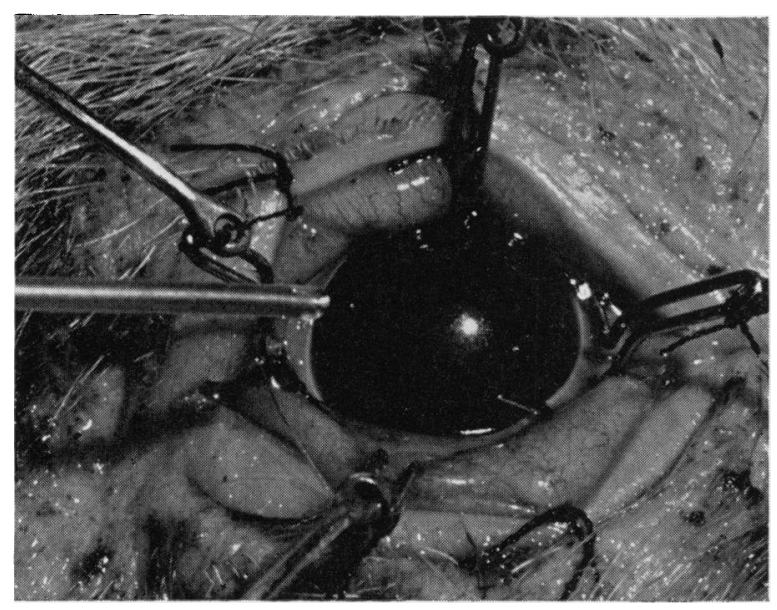

FIG. I Externalview of pig eye, showing modified Flieringa ring attached to 4 micromanipulators

In the experiments on the rhesus monkeys, the position of the eye was controlled by moving the animal's head on a special head-rest, the lids being kept open by a speculum.

\section{Pressure recording}

In six of the pig experiments, a continuous recording of the intraocular pressure was made in order to have an accurate measurement of the perfusing pressure of the retinal circulation. A 25 gauge needle was inserted into the anterior chamber at the limbus and connected by a catheter and threeway tap to a strain-gauge transducer and Devices $M_{4}$ recorder on the one hand and to an adjustable saline reservoir on the other. By this method a constant intraocular pressure could be maintained and recorded. In the remaining eleven animals an intraocular pressure of $16 \mathrm{~mm}$. $\mathrm{Hg}$ was assumed.

\section{Papaverine administration}

Papaverine hydrochloride 2.5 per cent. was infused intra-arterially through a 25 gauge needle inserted into the exposed common carotid artery in the neck, or intravenously through a $\mathrm{P} 60$ catheter placed in the femoral vein. Retrobulbar injections of papaverine were also given using a standard retrobulbar needle.

\section{Photography}

Circulation studies were made using fluorescein angiography and colour photography. Fluorescein and papaverine form an insoluble yellow precipitate when mixed together since fluorescein precipitates out in an acid solution; it was therefore necessary to inject fluorescein by an alternative arterial route to the acid papaverine. Injections were made through a catheter threaded via an ear artery into the common carotid well above the level of the papaverine infusion. About $0.5 \mathrm{ml}$. of Io per cent. fluorescein sodium solution was injected rapidly for each angiogram.

Retinal photography was performed using a vertically mounted Zeiss fundus camera. Colour photographs were taken with $35 \mathrm{~mm}$. Kodachrome II film, and for the fluorescein angiography $35 \mathrm{~mm}$. Kodak TriX film was used after the insertion of a Baird Atomic B 4 exciting filter and a Zeiss 
300976 barrier filter in the light pathway of the camera. The TriX film was force processed in undiluted $\mathrm{D}_{7} 6$ at room temperature for $14 \frac{1}{2} \mathrm{~min}$. Ciné-angiography was performed on Ilford Mark V film, using a Bolex $\mathrm{H} 16 \mathrm{~mm}$. camera adapted for use on the vertical fundus camera mounting. The frame speed was in the region of 30 frames per second, and the film was forced processed in undiluted Kodak D i9 developer.

Data measurements

(I) VESSEL DIAMETERS

Arteries and veins of approximately гоo $\mu$ in diameter were studied; the area chosen was usually the superior temporal region, this being the area of the fundus most accessible to examination, and the $\overrightarrow{0}$ area adjacent to the optic disc. Retinal vessel diameters were measured from the colour photographs or from the ciné film negatives, using a microscope with a micrometer scale in the ocular head. The total internal diameter of the vessels was taken to be the width of fluorescein within them when the vessel was full (Bulpitt, Dollery, and Kohner, 1970) and, using the micrometer, the standard deviation of a single measurement of a vessel of $100 \mu$ was found to be $\mathrm{r} \cdot 6 \mu$ for the arteries and $0.5 \mu$ for the veins when measured on $35 \mathrm{~mm}$. film, whereas it was $2.4 \mu$ for the arteries and $1 \mu$ ! for the veins on the cine film. Despite the loss in accuracy when compared with measurements from the $35 \mathrm{~mm}$. film, most calculations were made from the ciné angiograms. There were two reasons for this;

(i) It was not always possible to be sure that a vessel being measured was completely filled with fluorescein when a single photograph was taken, whereas on the ciné film the point of maximum filling (and therefore the true internal diameter) could be observed by frame-to-frame analysis.

(ii) Measurement of the vessel diameters from cine films meant that the vessel width could bs determined at the same time as the velocity of the dye front passing along it, whereas there was a gaß in time when $35 \mathrm{~mm}$. film was used, caused by having to change the cameras.

These advantages more than compensated for the less accurate measurements from ciné film.

\section{(2) DYE-FRONT VELOGITY}

The velocity of the fluorescein dye front along the artery under observation was measured by frameto-frame analysis using a Vanguard Motion Analyser. A section of an artery was chosen which was straight and which had no major branches, and the high-contrast photography enabled the progression of the fluorescein bolus along the vessel to be easily visualized (Bulpitt and Dollery, 1970). Diameter measurements were taken at both ends of the section under observation. The absolute value for dye-front velocity has to be adjusted for the individual magnification of the optical system of the eye under observation. The dye-front velocity is therefore presented in arbitrary units and changes in velocity are recorded as a percentage change of the normal in each experimental animal.

(3) VOLUME FLOW

Originally it was assumed that Poiseiulle flow existed in retinal arteries of the size that have been examined, so that the volume of blood flowing along these vessels (Volume Flow) could be expressed by the formula:

$$
\mathrm{F}=\frac{\pi r^{2} v k}{2}
$$

where $k$ is a magnification constant, $r$ is the radius in arbitrary units, and $v$ is the dye front velocity in arbitrary units per minute.

Volume flow therefore varies directly with the square of the radius $(r)$ and the dye front velocity (v). Studies by Bulpitt, Kohner, and Dollery (1973) suggest that Poseuille flow does not exist in these small vessels, but rather plug flow or some intermediate configuration. It was assumed that the flow profile showed little alteration throughout the experiment, and volume flow was expressed in arbitrary volume units per minute, and where comparative studies were made in the same animal variations in volume flow were expressed as percentage changes. 


\section{(4) PERFUSION PRESSURE}

For the purpose of these experiments the perfusion pressure was taken as the mean blood pressure (Diastolic $+1 / 3$ systolic-diastolic difference) minus the intraocular pressure. No allowance was made for the difference between the pressures measured in the aorta and those in the central retinal artery, since the technique of ophthalmodynamometry cannot be applied to the pig to measure ophthalmic artery pressure because of the different origin of the retinal vessels. It was assumed that the drop in pressure between the aorta and the central retinal artery was constant during the experiment provided that the circulation remained healthy.

\section{Results}

The following parameters were measured during intra-arterial and intravenous infusion of papaverine: retinal arterial and venous diameters, arterial blood flow velocity, and volume flow. In addition, separate experiments were undertaken to determine the dose/ response curve for papaverine and to measure the cardiac output during the infusion.

(1) Dose/response measurements

Fig. 2 shows the response of arterial diameter, dye-front velocity, and volume flow to graded doses of 2.5 per cent. papaverine hydrochloride infused at a constant rate into the

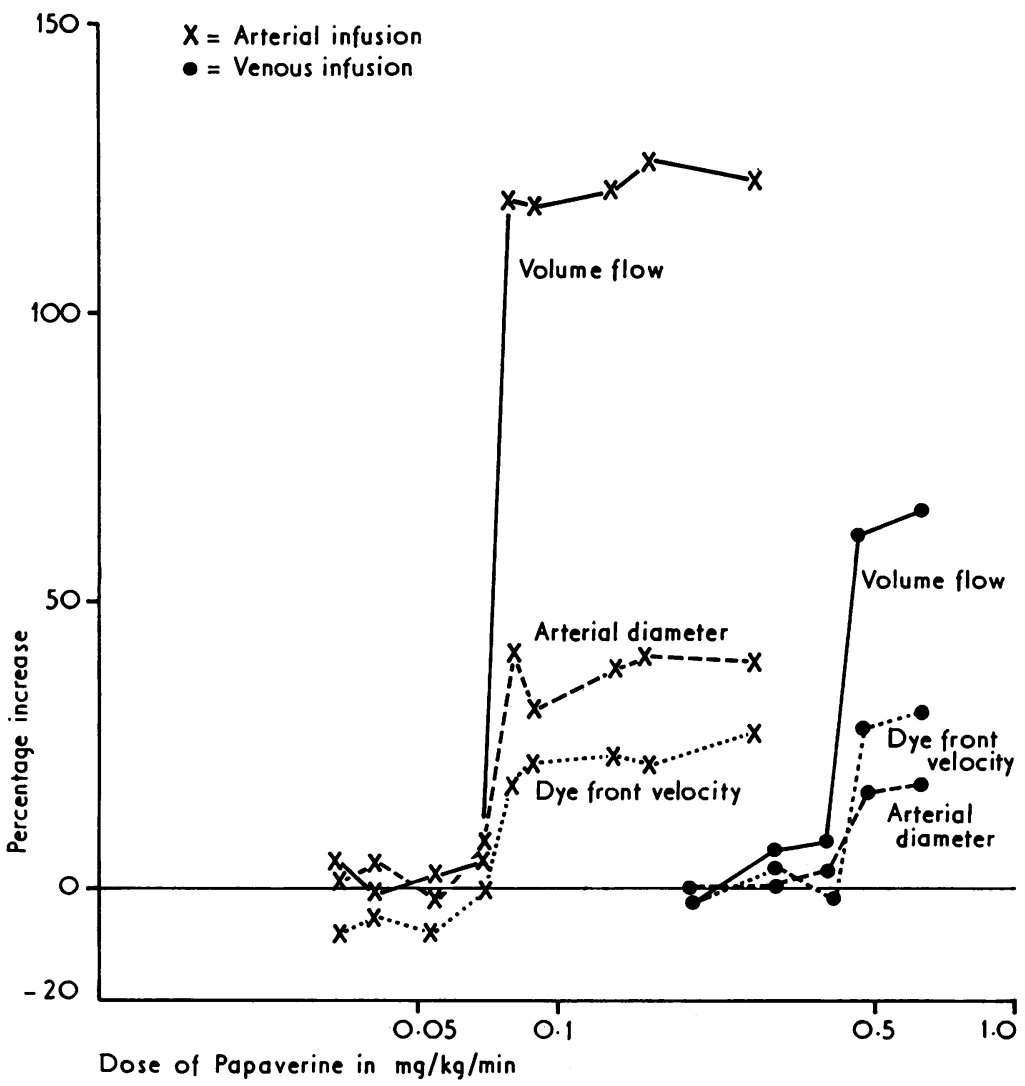

FIG. 2 Dose response curves for papaverine infusions, showing changes in volume flow, dye-front velocity, and arterial diameter for both arterial and venous infusions 
carotid artery of the pig. All three parameters showed a steep increase when the amoun of papaverine infused exceeded $0.08 \mathrm{mg}$. $/ \mathrm{kg}$. $/ \mathrm{min}$., and at doses above this value there was no further increase in arterial diameter and velocity. A similar curve is shown during. intravenous infusions of graded doses of papaverine with a threshold level of $0.45 \mathrm{mg} . / \mathrm{kg}$. $\stackrel{\rho}{f}$ min. The arterial diameter was found to be an accurate index of the volume flow and the steep slope of the curve suggested that the vasodilator effect of papaverine occurred when an active intraluminal concentration of the drug was reached. Dose/response measure

ments were not obtained in the monkeys.
For the purpose of the experiments papaverine was infused at about twice the threshold dose and at this level no cardiac irregularity or change in the systemic circulation wasobserved. At very high doses (ten times threshold) the systemic blood pressure fell leading to circulatory collapse.

\section{(2) Vessel diameter changes}

Alterations in vessel calibre were calculated as percentage changes of the control; theo changes in arterial and venous diameter during intra-arterial and intravenous infusions of papaverine are given in Tables I and II. The percentage changes were obtained by examining selected vessels in each animal and the papaverine was given intra-arterially or intravenously for at least io minutes on an average of two or three occasions per animal

Table I Intra-arterial infusion

\begin{tabular}{|c|c|c|c|c|c|c|}
\hline \multicolumn{4}{|c|}{ Arterial diameter } & \multicolumn{3}{|c|}{ Venous diameter } \\
\hline Pig no. & Control & $\begin{array}{l}\text { During } \\
\text { infusion }\end{array}$ & $\begin{array}{l}\text { Per cent. } \\
\text { change }\end{array}$ & Control & $\begin{array}{l}\text { During } \\
\text { infusion }\end{array}$ & $\begin{array}{l}\text { Per cent. } \\
\text { change }\end{array}$ \\
\hline 253 & I 06 & 144 & +36 & 204 & 281 & $+3^{8}$ \\
\hline 255 & I 48 & I 88 & +23 & 210 & 222 & +6 \\
\hline 259 & I 18 & I 70 & +44 & 236 & 298 & +26 \\
\hline $26 I$ & 120 & I 5 I & +26 & 232 & 232 & - \\
\hline 277 & 9 I & 93 & $+3 \mathbf{I}$ & 87 & I I 5 & $+3^{2}$ \\
\hline $29 I$ & I I 7 & I 47 & +26 & 220 & $24^{8}$ & +13 \\
\hline 289 & 104 & I 47 & $+4 I$ & I 82 & 204 & +12 \\
\hline \multicolumn{7}{|l|}{$\begin{array}{l}\text { Monkey } \\
\text { no. }\end{array}$} \\
\hline 26 & 67 & 87 & +30 & 95 & I 26 & $+3^{2}$ \\
\hline 27 & 71 & 93 & $+3 \mathbf{I}$ & 93 & 124 & +33 \\
\hline
\end{tabular}

The figures show an average increase of 33 per cent. of the arterial diameter duringo intra-arterial infusion, and an average of 18 per cent. increase in the venous diameter these increases being demonstrated in first and second order vessels. The results in the two monkey experiments showed comparable increases. Analysis of the intravenou results showed an average increase of $3^{2}$ per cent. of the arterial diameter during infusior and 77 per cent. of the venous diameter.

The calibre changes started within i5 sec. of the commencement of the infusion by arterial route and were fully established within 30 sec., there was a predictable delay in the onset of dilatation when papaverine was infused intravenously, but the vessel changes took place with equal rapidity. After the cessation of the infusion the speed at which the dilator effect wore off was variable. Diameter measurement 
Table II Intravenous infusion

\begin{tabular}{|c|c|c|c|c|c|c|}
\hline \multicolumn{4}{|c|}{ Arterial diameter } & \multicolumn{3}{|c|}{ Venous diameter } \\
\hline Pig no. & Control & $\begin{array}{l}\text { During } \\
\text { infusion }\end{array}$ & $\begin{array}{l}\text { Per cent. } \\
\text { change }\end{array}$ & Control & $\begin{array}{l}\text { During } \\
\text { infusion }\end{array}$ & $\begin{array}{l}\text { Per cent } \\
\text { change }\end{array}$ \\
\hline 262 & I I 9 & 169 & $+4^{\circ}$ & I 45 & I 80 & +24 \\
\hline 266 & 134 & 187 & +39 & $25^{\circ}$ & 287 & +15 \\
\hline 271 & 124 & I 68 & +35 & 235 & $28 \mathrm{I}$ & +20 \\
\hline 272 & IO4 & 141 & +36 & I 68 & I 92 & +14 \\
\hline 273 & 107 & I 41 & +32 & I 12 & I 28 & +14 \\
\hline $29^{8}$ & 88 & I 15 & $+3 I$ & 180 & 220 & $\div 22$ \\
\hline 304 & ${ }^{1} 5^{\circ}$ & 167 & +12 & $24^{8}$ & 282 & +14 \\
\hline $33^{6}$ & 102 & 132 & +29 & 192 & 215 & +12 \\
\hline $34^{\circ}$ & IIO & 142 & +29 & 180 & 225 & +24 \\
\hline 343 & 97 & 127 & $+3^{I}$ & 157 & I 75 & +12 \\
\hline 344 & 85 & I 25 & +47 & 95 & 115 & $+2 I$ \\
\hline 345 & 115 & I 35 & +17 & 125 & I 35 & +8 \\
\hline \multicolumn{7}{|l|}{$\begin{array}{l}\text { Monkey } \\
\text { no. }\end{array}$} \\
\hline 18 & 66 & 75 & +14 & 112 & 120 & +7 \\
\hline
\end{tabular}

taken at $5 \mathrm{~min}$. intervals after the termination of a $\mathrm{s}$-min. intra-arterial infusion of papaverine in two pigs ( 255 and 259 ) showed that the retinal arteries remained dilated for 25 and $40 \mathrm{~min}$. respectively. In pigs 262 and 266, where intravenous papaverine was given, the dilator effect wore off in 35 and 40 min. respectively. An interval of at least $45 \mathrm{~min}$. was allowed between successive infusion studies, and this was extended if the retinal arteries remained dilated after this period. Dilatation of the whole retinal and choroidal vascular tree was evident during the infusions, with the retinal arteries becoming more tortuous and the capillaries filling more rapidly, although they remained impermeable to fluorescein and no leakage was observed.

\section{(3) Blood velocity changes}

Dye-front velocities were measured in the retinal arteries under investigation during intraarterial and intravenous infusions, and the results, expressed as a percentage change of the control velocity are given in Table III and Table IV (overleaf). The perfusion pressure during each infusion is also recorded.

Unlike the changes in the vessel diameters, the velocity was seen to vary within wide limits, being largely influenced by alterations in the perfusion pressure; the relationship between these two measurements is seen in Fig. 3. At the commencement of the papaverine infusion, there was a transient rise in the intraocular pressure of about $5 \mathrm{~mm}$. $\mathrm{Hg}$ which was thought to be related to the increased volume of blood in the choroid. The pressure rise soon fell to levels below normal according to the drop in mean blood pressure.

\section{(4) Choroidal changes}

During papaverine infusion, the choroidal background became pinker and, although the normal type of segmental filling occurred, the time intervals between filling of the separate segments were reduced. A quantitative assessment of the rate of choroidal filling was not possible but appeared to correlate with the dye-front velocity. The interval of time 
Table III Dye-front velocity changes during intraarterial infusion

\begin{tabular}{|c|c|c|c|c|c|}
\hline \multicolumn{3}{|c|}{ Perfusion pressure $(\mathrm{mm} . \mathrm{Hg})$} & \multicolumn{3}{|c|}{ Dye-front velocity (units/min.) } \\
\hline Pig no. & $\begin{array}{l}\text { During } \\
\text { infusion }\end{array}$ & $\begin{array}{l}\text { Per cent. } \\
\text { of control }\end{array}$ & Control & $\begin{array}{l}\text { During } \\
\text { infusion }\end{array}$ & $\begin{array}{l}\text { Per cent. } \\
\text { change }\end{array}$ \\
\hline 253 & IOI & 97 & 173 & 292 & +68 \\
\hline 259 & 105 & 89 & I 54 & 200 & +36 \\
\hline 261 & 53 & $5^{6}$ & 107 & 107 & +0 \\
\hline 277 & 64 & 84 & 102 & 157 & +54 \\
\hline 291 & $5^{6}$ & 64 & 168 & I 76 & - \\
\hline 289 & 100 & 96 & 143 & 247 & +72 \\
\hline \multicolumn{6}{|l|}{$\begin{array}{l}\text { Monkey } \\
\text { no. }\end{array}$} \\
\hline 26 & 90 & 85 & 113 & 127 & +13 \\
\hline 27 & 75 & 95 & ${ }^{1} 53$ & 179 & +17 \\
\hline
\end{tabular}

Table IV Dye-front velocity changes during intravenous infusion

\begin{tabular}{|c|c|c|c|c|c|}
\hline \multicolumn{3}{|c|}{ Perfusion pressure $(\mathrm{mm} . \mathrm{Hg})$} & \multicolumn{3}{|c|}{ Dye-front velocity (units/min.) } \\
\hline Pig no. & $\begin{array}{l}\text { During } \\
\text { infusion }\end{array}$ & $\begin{array}{l}\text { Per cent. } \\
\text { of control }\end{array}$ & Control & $\begin{array}{l}\text { During } \\
\text { infusion }\end{array}$ & $\begin{array}{l}\text { Per cent. } \\
\text { change }\end{array}$ \\
\hline 262 & 67 & 72 & 109 & 147 & +25 \\
\hline 266 & 96 & 96 & 193 & 270 & +40 \\
\hline 271 & 30 & 50 & 320 & 227 & -29 \\
\hline 272 & $5^{1}$ & 53 & 171 & 151 & -12 \\
\hline 273 & 78 & 87 & 125 & 208 & +66 \\
\hline 298 & $3^{2}$ & $5^{8}$ & 65 & 68 & +4 \\
\hline 304 & 54 & 67 & 274 & 353 & +29 \\
\hline 336 & $4^{1}$ & 79 & 230 & 284 & +24 \\
\hline 340 & 53 & 90 & I10 & I 64 & +49 \\
\hline 343 & 30 & 55 & 145 & 1 38 & -5 \\
\hline 344 & 43 & 82 & 118 & 191 & +62 \\
\hline 345 & 71 & 98 & 209 & 303 & +45 \\
\hline \multicolumn{6}{|l|}{$\begin{array}{l}\overline{\text { Monkey }} \\
\text { no. }\end{array}$} \\
\hline 18 & $5^{2}$ & 76 & 104 & 129 & +24 \\
\hline
\end{tabular}

between the onset of choroidal and retinal filling in a specific area-the choroido-retinal $N$ time (C-R time) - was not significantly altered during infusion by either route although it was prolonged if the blood pressure fell substantially.

(5) Volume flow changes

Increases in volume flow during intra-arterial and intravenous infusions are shown in Table V and VI (overleaf), together with the perfusion pressure.

Analysis of these results show an average increase of 140 per cent. of the volume flow 


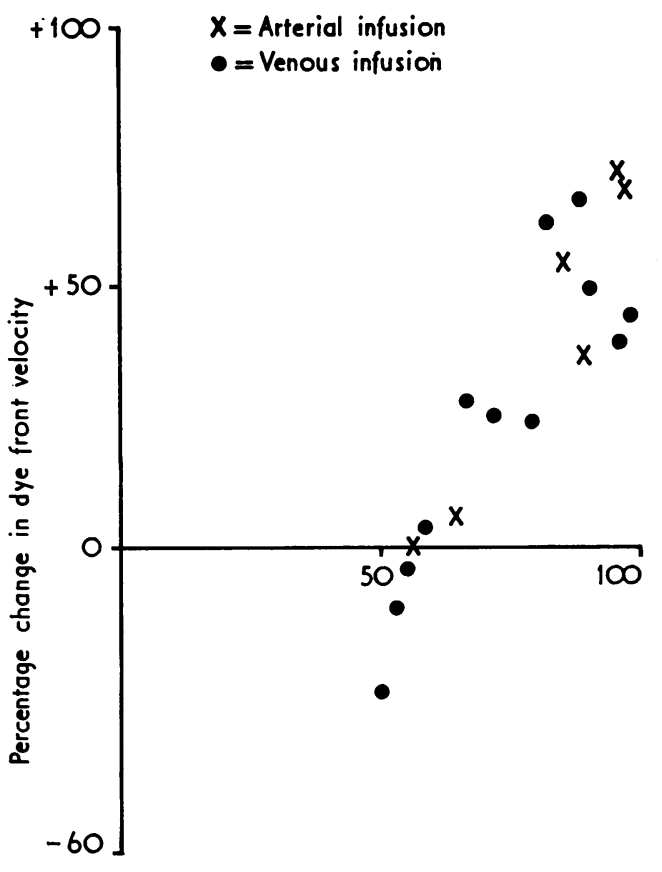

Percentage of control perfusion pre ssure

FIG. 3 Changes in dye-front velocity due to fall in perfusion pressure during papaverine infusions

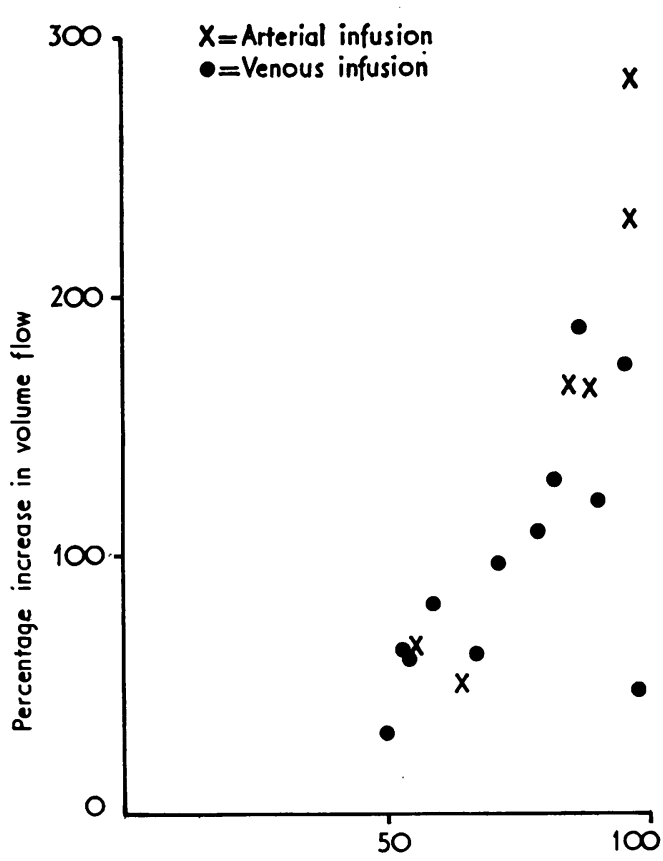

Percentage of control perfusion pressure

FI G. 4 Relationship of increased volume flow to fall in perfusion pressure during papaverine infusions

during intra-arterial infusion of papaverine, and the average increase after intravenous infusion was 96 per cent. There was no significant difference between the increase in flow produced by intra-arterial and intravenous routes $(P>0 \cdot I)$. There was a wide variation in the results and this was related to the alteration in perfusion pressure during the experiment. The systemic administration of papaverine causes a fall in retinal perfusion pressure, and a more meaningful picture of the effect of papaverine on the volume flow can be obtained if the volume flow is plotted against the fall in perfusion pressure represented by the percentage, during infusion, of the normal level (Fig. 4).

\section{(6) Effect on cardiac output}

In two animals, the cardiac output was measured by the dye dilution technique during infusions of suprathreshold doses of papaverine by intra-arterial and intravenous routes. At a dose of $0.25 \mathrm{mg}$. $/ \mathrm{kg}$. $/ \mathrm{min}$. intra-arterially there was a $5^{\mathrm{I}}$ per cent. increase in cardiac output with an average fall in mean blood pressure of 18 per cent. and an increase in pulse rate of io per cent. By the intravenous route, where the dose of papaverine was larger, an infusion of $0.8 \mathrm{mg} . / \mathrm{kg} . / \mathrm{min}$. caused an increase of $67 \mathrm{per}$ cent. in the cardiac output, the mean blood pressure fell by 24 per cent. and there was a 16 per cent. increase in pulse rate. No change in the cardiac output was recorded after a single retrobulbar injection of $\mathrm{I} \mathrm{ml}$. of 2.5 per cent. papaverine hydrochloride. Estimation of the blood $\mathrm{pH}, \mathrm{pCO}_{2}$, and $\mathrm{pO}_{2}$ showed no major alterations during the infusions.

\section{(7) Effect of retrobulbar injection}

In two experiments in the pig, I $\mathrm{ml}$. of 2.5 per cent. papaverine was given by standard 
Table $\mathbf{V}$ Volume flow change during intra-arterial infusion

\begin{tabular}{|c|c|c|c|c|c|}
\hline \multicolumn{3}{|c|}{ Perfusion pressure $(\mathrm{mm} . \mathrm{Hg})$} & \multicolumn{3}{|c|}{ Dye-front velocity (units/min.) } \\
\hline Pig no. & $\begin{array}{l}\text { During } \\
\text { infusion }\end{array}$ & $\begin{array}{l}\text { Per cent. } \\
\text { of control }\end{array}$ & Control & $\begin{array}{l}\text { During } \\
\text { infusion }\end{array}$ & $\begin{array}{l}\text { Per cent } \\
\text { change }\end{array}$ \\
\hline 253 & 101 & 97 & $\cdot 0023$ & $\cdot 0076$ & +230 \\
\hline 259 & 105 & 89 & .0027 & $\cdot 0072$ & +166 \\
\hline 261 & 53 & $5^{6}$ & .0019 & $\cdot 003^{I}$ & +63 \\
\hline 277 & 64 & 84 & .0006 & $\cdot 0016$ & +166 \\
\hline 291 & $5^{6}$ & 64 & .0032 & $\cdot 0048$ & +50 \\
\hline 289 & 100 & 96 & $\cdot 0019$ & $\cdot 0072$ & +284 \\
\hline \multicolumn{6}{|l|}{$\begin{array}{l}\text { Monkey } \\
\text { no. }\end{array}$} \\
\hline 26 & 90 & 85 & $\cdot 0006$ & .0012 & +100 \\
\hline 27 & 75 & 95 & .0012 & $\cdot 0019$ & $+5^{8}$ \\
\hline
\end{tabular}

Table VI Volume flow changes during intravenous infusion

\begin{tabular}{|c|c|c|c|c|c|}
\hline \multicolumn{3}{|c|}{ Perfusion pressure $(\mathrm{mm} . \mathrm{Hg})$} & \multicolumn{3}{|c|}{ Dye-front velocity (units/min.) } \\
\hline Pig no. & $\begin{array}{l}\text { During } \\
\text { infusion }\end{array}$ & $\begin{array}{l}\text { Per cent. } \\
\text { of control }\end{array}$ & Control & $\begin{array}{l}\text { During } \\
\text { infusion }\end{array}$ & $\begin{array}{l}\text { Per cent. } \\
\text { change }\end{array}$ \\
\hline 262 & 67 & 72 & $\cdot 0033$ & $\cdot 005^{I}$ & +96 \\
\hline 266 & 95 & 96 & $\cdot 0043$ & . 0118 & +174 \\
\hline 271 & 30 & $5^{0}$ & $\cdot 006 \mathrm{I}$ & $\cdot 008 \mathbf{r}$ & +31 \\
\hline 272 & $5^{1}$ & 53 & $\cdot 0023$ & $\cdot 0038$ & +65 \\
\hline 273 & 78 & 87 & .0018 & $\cdot 005^{2}$ & +189 \\
\hline 298 & $3^{2}$ & $5^{8}$ & $\cdot 0006$ & .0011 & +83 \\
\hline 304 & 54 & 67 & .0077 & .0125 & +62 \\
\hline $33^{6}$ & $4^{1}$ & 79 & .0047 & $\cdot 0099$ & +110 \\
\hline 340 & 53 & 90 & $\cdot 0028$ & $\cdot 0066$ & +121 \\
\hline 343 & 30 & 55 & $\cdot 0028$ & .0045 & +60 \\
\hline 344 & 43 & 82 & .0017 & $\cdot 0039$ & +130 \\
\hline 345 & 71 & 98 & $\cdot 006 \mathbf{I}$ & $\cdot 0093$ & +48 \\
\hline \multicolumn{6}{|l|}{$\begin{array}{l}\overline{\text { Monkey }} \\
\text { no. }\end{array}$} \\
\hline 18 & $5^{2}$ & 76 & $\cdot 0005$ & $\cdot 0009$ & +80 \\
\hline
\end{tabular}

retrobulbar injection into the cone of muscles. No significant alteration in the diameter of the retinal vessels could be demonstrated and there was no change in the dye-front velocity

\section{Discussion}

Papaverine hydrochloride is a benzylisoquinoline derivative found in opium. It is $a^{\mathbb{N}}$ smooth-muscle relaxant which has been known for a long time and has been used for the treatment of coronary arterial disease (Elek and Katz, I942), of mesenteric and pulmonary品 
emboli, and of peripheral arterial osclusions, where it is said to be effective in opening up anastomotic channels and overcoming reflex spasm (de Takats, 1936). It has also been used in the treatment of cerebral ischaemia and hypertensive encephalopathy (McHenry, Jaffe, Kawamura, and Goldberg, 1970). It has been found to be effective on cerebral vessels in humans (Jayne, Scheinberg, Rich, Belle, and Blackburn, I952; Morello, Bartecek, Stellar, and Cooper, 1956), and dilatation of the retinal vessels has been described by Lende and Ellis (1964) in cats, and by Gombos (1971), and de Rivas Cherif (1967) in man. Retinal artery dilatation was not observed in experiments in man by Frayser and Hickam ( 1965 ) when papaverine was given by single intravenous injections.

The present studies show that papaverine produces a marked dilatation of the retinal vessels when infused by arterial or venous routes with a significant increase in the volume flow through the retinal circulation. Figs 3 and 4 show that these increases diminish as the perfusion pressure falls in response to the systemic effect of the vasodilator, so that the dye-front velocity becomes less than normal at a perfusion pressure of 50 per cent. of the control (Fig. 3), although in no experimental situation did the volume flow fall below control levels (Fig. 4). This continued increase in volume flow despite low perfusion pressures was the result of sustained retinal artery dilatation.

The explanation for this effect of systemically infused papaverine on the retinal circulation may depend on the lack of innervation of the retinal arteries. The general fall in peripheral resistance that accompanies the infusion of this vasodilator leads to a reflex stimulation of the sympathetic system with an associated increase in sympathetic tone in the peripheral vessels overcoming the effect of the drug. Massive doses of papaverine may override this sympathetic action and a profound fall in blood pressure follows. The retinal circulation does not have a sympathetic supply and therefore no reflex constriction occurs; consequently it remains a dilated vascular bed associated with an increased cardiac output during the infusion, and a greater retinal volume flow is produced.

The failure of retrobulbar papaverine to influence either modality of retinal blood flow can be explained by consideration of its direct action on blood vessesl. Lende and Ellis ( 1964 ) showed, in their experiments on exposed retinal vessels in cats, that papaverine was the most effective topical vasodilator, overcoming spasm when applied to the artery. This dilatation was localized, did not spread distally or proximally along the vessel, and lasted for only a few minutes. Even assuming that a retrobulbar injection delivers sufficient quantities of papaverine into the immediate vicinity of the ophthalmic arteryand most retrobulbar injections lack this degree of accuracy-, localized dilatation of the artery would be produced without propagation along the vessel into the eye. Such a local dilatation would have a minimal haemodynamic effect on the distal circulation and no improvement of volume flow would be seen.

Papaverine was shown to be a potent retinal vasodilator when delivered in sufficient concentration into the systemic circulation. Above a threshold concentration, an increase in volume flow in the retinal circulation was maintained, although it diminished if the systemic dose of papaverine reduced the retinal perfusion pressure.

Retinal arteries may become occluded through a variety of factors. They may undergo spasm, they may be blocked by various sorts of emboli, or they may become obstructed as the result of disease in the vessel wall leading to a severe narrowing of their lumen. The results of these experiments suggest that papaverine may play a role in the management of occlusions caused by spasm or emboli. The spasmolytic action of the drug has been discussed and in the case of emboli the improved perfusion caused by the drug may help to maintain oxygenation by increasing the flow of blood through the choroidal circulation 
and by opening up collateral channels in the retina. With emboli, dilatation of the artery around the embolus may encourage it to move more peripherally in the vessel.

The most effective method of delivery would be into the obstructed artery itself; by this means the systemic response to the drug would be minimized. Varley and others (1968)离 have shown that infusions of papaverine into the ophthalmic artery via the supra-orbitale artery can be successful in overcoming retinal artery spasm and dilatation of the whole $\frac{\bar{\sigma}}{\overline{0}}$ of the carotid system has been observed after carotid injection of papaverine (Morello and others, 1956). The risks and difficulties of arterial infusions may, however, outweigh the theoretical advantages. Intravenous infusion produces a comparable retinal artery dilatation and the improvement in volume flow is related inversely to the fall in mean. blood pressure. An intravenous infusion, therefore, in which the mean blood pressurew was not allowed to fall by more than 20 per cent. would produce an increase in volumeof flow of more than Ioo per cent. (see Fig. 4). Retrobulbar injections of papaverine were not found to have an effect.

\section{Summary}

Papaverine hydrochloride was infused intra-arterially and intravenously in pigs ando monkeys. The haemodynamic changes in the retinal circulation were measured. There was an average dilatation of the retinal arteries of 33 per cent. when given by either route. The volume flow through the retina was increased by an average of I 8 per cent. when papaverine was given intra-arterially or intravenously, the increase depending on the retinal perfusion pressure which fell by an average of 2 I per cent. during the infusions. $\stackrel{\oplus}{-}$ Retrobulbar injections of papaverine did not have any effect on the retinal circulation

The possible value of papaverine in the management of acute occlusions of the retima arteries is discussed.

We wish to acknowledge the help given in these experiments by Mr. M. Tudball and by the technical staft of the Department of Clinical Pharmacology, Royal Postgraduate Medical School, Hammersmith Hospital ٌ We are indebted to Mr. T. Tarrant and the Audiovisual Department, Institute of Ophthalmology, for the illustrations, and we are grateful for the secretarial assistance of Miss Josephine Lace.

This work was supported by grants from the Wellcome Trust and from the Tobacco Research Council.

\section{References}

AShton, N., DOllery, C. T., Henkind, P., HILl, D. W., PATERSON, J. W., RAMAlHo, P. S., and SHAKIB, M.

(1966) Brit. J. Ophthal., 50, 283

BUlPitT, c. J., and DOllery, c. T. (1970) Brit. Kinematography Sound and Television, 52, 14

$\longrightarrow$, $\longrightarrow$ and Kohner, E. M. (1970) Cardiovasc. Res., 4, 207

- KOHNER, E. M., and DOLlery, C. T. (1973) Bibl, anat, (Basel), Ir, 448

de takats, G. (1936) J. Amer. med. Ass., ro6, 1003

ELEK, s. R., and KATZ, L. N. (1942) Ibid., r20, 434

FrAYSER, R., and hickAM, J. B. (I965) Arch. Ophthal. (Chicago), 73, 640

GomBos, G. м. (1970) Ann. Ophthal., 2, 893

HENKIND, P. (1967) Invest. Ophthal., 6, I03

JAYNE, H. W., SGHEINBERG, P., RICH, M., BELLE, M. S., and BLAGKBURN, I. (1952)

LENDE, R. A., and Ellis, P. P. (I964) Arch. Ophthal. (Chicago), 7r, 70 I

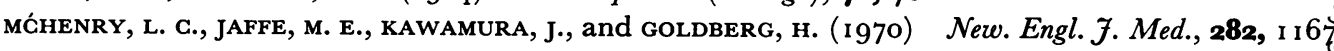
morello, A., Bartecek. A., stellar, s., and cooper, i. (1956) Angiology, 7, i6

RIVAS CHERIF, M. DE (1967) An. Soc. mex. Oftal., 40, 50

ROOTMAN, J. (1971) Brit. 7. Ophthal., 55, 808

VARLey, E. W. B., HOLt-wilson, A. D., and Watson, P. G. (1968) Brit. J. oral Surg., 6, 3 I

zAHN, K. (1966) Trans. ophthal. Soc. U.K., 86, 529 